\title{
Development of Budesonide Oral Colon Specific Drug Delivery System using Interpolymer Complexation Method
}

\author{
Patil Ramgonda, Rajashree Shashidhar Masareddy*, Archana Patil, Uday Bolmal
}

Department of Pharmaceutics, JNMC Campus, KLE Academy of Higher Education and Research, KLE College of Pharmacy, Belagavi, Karnataka, INDIA.

\begin{abstract}
Background: Oral bioavailability of Budesonide is $10 \%$ due to its extensive first pass metabolism, its high volume of distribution and $85-90 \%$ of protein binding. Protection of drug release in stomach and targeting drug to colon which is an absorption site of drug is an attempt to improve therapeutic efficacy. The objective of this study was to develop interpolymer complex microspheres of Budesonide for oral colon specific drug delivery. Methods: Emulsion solvent evaporation method was used in the preparation of microspheres. Microspheres prepared at different polymer ratio and surfactant concentration were analysed for its mean particle size, surface morphology, flow property, drug release, \% encapsulation efficiency. Results: Microspheres prepared with $3: 5$ polymer ratios $\mathrm{F} 4$ was optimized with respect to its $\% \mathrm{EE}$, in vitro drug release and percentage yield. Drug release from formulated tablets containing microspheres of 3:5 polymer ratios showed an extended release up to $12 \mathrm{~h}$ in $\mathrm{pH}$ buffer 7.4. Interpolymer complexation was confirmed by FT-IR studies, compatibility of drug with excipients by DSC indicated no significant changes with drug. SEM studies revealed formation of round microspheres with pervious and uneven surface. In vitro release data from microspheres was analysed by kinetic model fitting for mechanism of drug release. Microspheres showed $5-10 \%$ of drug release in $\mathrm{pH} 1.2$ which was further prevented by formulating coated tablets of microspheres using cellulose acetate phthalate. Conclusion: Targeted colon specific drug delivery of Budenoside with extended release up to $12 \mathrm{~h}$ was successfully achieved by formulation of tablets containing microspheres prepared by interpolymer complexation technique.
\end{abstract}

Key words: Budesonide, Colon Specific Delivery, Interpolymer Complexation, Microspheres, Cellulose Acetate phthalate.

\section{INTRODUCTION}

Targeted drug delivery is an exclusive drug delivery system where drug is delivered specifically to the site of absorption or where action is desired and not surrounding tissues or cells. This method of targeting helps in delivery of medication at high concentration to target site which helps in improving efficacy and reducing side effects. Oral targeted delivery systems are best suitable for drugs having instability, low solubility and short half-life, a large volume of distribution, poor absorption, low specificity and narrow therapeutic index.
Targeting drug to absorption site provides maximum therapeutic activity thereby reducing dose of drug which reduces toxicity to potent drugs and minimizes adverse effects. ${ }^{1-5}$ Colon targeted drug delivery systems are used for the therapy of local colonic diseases like crohn's disease and ulcerative colitis. The different approaches include prodrug, $\mathrm{pH}$ and time dependent systems, microbial activated system, timed release system, osmotically controlled drug delivery system and pressure dependent release system. .,7 $^{2}$
Submission Date: 29-06-2020; Revision Date: 15-08-2020; Accepted Date: 12-12-2020

DOI: 10.5530/ijper.55.1s.47 Correspondence: Prof. Rajashree S Masareddy Professor and Head, Department of Pharmaceutics, KLE Academy of Higher Education and Research, KLE College of Pharmacy, Nehru Nagar, Belagavi-590010, Karnataka, INDIA.

Phone: +91 9448901848

E-mail: rsmasareddy@ rediffmail.com

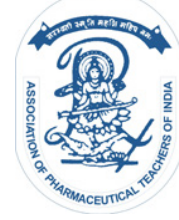

www.ijper.org 
Budesonide belongs to BCS class II, $2^{\text {nd }}$ generation antiinflammatory glucocorticoid used in the treatment of inflammatory bowel disease having biological half-life of 2.0-3.6 $\mathrm{h}$ excreted as its metabolites from the urine. Oral bioavailability of Budesonide is $10 \%$ due to its considerable first pass metabolism, high volume of distribution, $85-90 \%$ of protein binding. It is a suitable candidate of choice for colon drug delivery since it is well absorbed in the colon. ${ }^{8}$

Interpolymer complex microspheres is an approach for colon targeting which uses two polymers to form complex, the use of complex results in the change of physico-chemical properties of polymer which restrain the drug release in the stomach and carry drug to the colon were degradation of polymer by colonic enzymes will result in drug release at target site. ${ }^{9-11}$

This study is an attempt to develop oral colon targeted drug delivery system of Budesonide by interpolymer complexation using Emulsion solvent evaporation method.

\section{MATERIALS AND METHODS}

\section{Materials}

Budesonide was obtained as a gift sample from Cipla Pvt. Ltd. Goa. Chitosan (medium molecular weight) and Cellulose acetate phthalate was procured from Yarrow Chemical Products, Mumbai, India. Light liquid paraffin procured from Loba Chemie Pvt. Ltd. Mumbai, India. Span 80 was procured from Hi-Media Laboratories Pvt. Ltd., Mumbai, India. Acetone and n-Hexane was procured from Molychem, Mumbai, India.

\section{Preparation of microspheres using emulsion solvent evaporation method}

Weighed quantity of chitosan was dissolved in $25 \mathrm{ml}$ of $5 \%$ acetic acid solution and kept on magnetic stirrer to form homogenous solution. The resulting mixture was then added to $100 \mathrm{ml}$ of light liquid paraffin containing varying concentration of surfactant (Span80) with continuous stirring using propeller speed of $600 \mathrm{rpm}$ for emulsification to form w/o emulsion.

In another beaker, required quantity of cellulose acetate phthalate was dissolved in $25 \mathrm{ml}$ of acetone: water (97:3) and placed on magnetic stirrer to form polymer solution. Weighed quantity of Budesonide was added to this polymer solution and mixed rigorously. This solution was transferred drop wise to the w/o emulsion formed in above step and stirred continuously with the help of propeller at $2000 \mathrm{rpm}$ for $3 \mathrm{~h}$ till acetone evaporated to form microspheres. The emulsion was allowed to settle for $2-3 \mathrm{~h}$ to separate the oil phase which was then decanted, drug loaded microspheres were washed repeatedly with n-Hexane and dried at room temperature to get free flowing microspheres. ${ }^{12,13}$ The Coded factors with their levels for composition of polymer ratio and surfactant concentration is shown in Table 1.

\section{Experimental design}

Experimental design using Design-Expert ${ }^{12}$ was used to check the effect of independent variables i.e. Polymer ratio (CS: CAP) and surfactant concentration on dependent variables i.e. $\% \mathrm{CDR}, \% \mathrm{EE}$ and mean particle size of microspheres. A $3^{2}$ full factorial design was used to prepare 9 formulations of microspheres. In this model two variables were evaluated individually at three levels. The coded values for higher, intermediate and lower were taken as $+1,0$ and -1 respectively. The coded and actual values of design are given in Table 2 .

\section{Evaluation of Microspheres}

\section{Size Distribution Analysis}

Average size of microspheres was determined using compound microscope at 10X resolution power lens. A small quantity of microspheres were suspended in water and spread on glass slide and average particle size for 100 microspheres was measured for each batch in triplicate. ${ }^{14}$

\begin{tabular}{|c|c|c|c|c|}
\hline \multicolumn{5}{|c|}{ Table 1: Coded factors with their levels. } \\
\hline Factors & Symbol & Low & Intermediate & High \\
\hline $\begin{array}{c}\text { Polymer Ratio } \\
\text { (CS:CAP) }\end{array}$ & $\mathrm{X}_{1}$ & -1 & 0 & 1 \\
\hline $\begin{array}{c}\text { Surfactant } \\
\text { Concentration } \\
\text { (span 80) }\end{array}$ & $\mathrm{X}_{2}$ & -1 & 0 & 1 \\
\hline
\end{tabular}

$*_{+1}=$ High, $0=$ Intermediate and $-1=$ Low concentratio

Table 2: Formulation of microspheres by $3^{2}$ factorial design using design expert ${ }^{\circledR} 12$ software.

\begin{tabular}{|c|c|c|c|c|c|}
\hline \multirow{2}{*}{$\begin{array}{c}\text { Formulation } \\
\text { code }\end{array}$} & \multicolumn{2}{|c|}{$\begin{array}{c}\text { Coded levels } \\
\text { of variables }\end{array}$} & \multicolumn{2}{|c|}{$\begin{array}{c}\text { Actual levels of } \\
\text { variables }\end{array}$} & \multirow{2}{*}{$\begin{array}{c}\text { Drug } \\
\text { (mg) }\end{array}$} \\
\cline { 2 - 5 } & $\mathbf{X}_{1}$ & $\mathbf{X}_{2}$ & $\mathbf{X}_{1}$ & $\mathbf{X}_{2}$ & \\
\hline F1 & -1 & -1 & $3: 5$ & 1 & 200 \\
\hline F2 & 0 & -1 & $4: 5$ & 1 & 200 \\
\hline F3 & 1 & -1 & $5: 5$ & 1 & 200 \\
\hline F4 & -1 & 0 & $3: 5$ & 1.5 & 200 \\
\hline F5 & 0 & 0 & $4: 5$ & 1.5 & 200 \\
\hline F6 & 1 & 0 & $5: 5$ & 1.5 & 200 \\
\hline F7 & -1 & 1 & $3: 5$ & 2 & 200 \\
\hline F8 & 0 & 1 & $4: 5$ & 2 & 200 \\
\hline F9 & 1 & 1 & $5: 5$ & 2 & 200 \\
\hline
\end{tabular}

Where, $\mathrm{X}_{1}=$ Polymer ratio and $\mathrm{X}_{2}=$ Surfactant concentration 


\section{Percentage Yield}

To determine the efficiency of method for the preparation of microspheres the percentage yield was calculated by noting the weight of microspheres obtained from each batch with respect to total weight of material. ${ }^{15}$ Percent yield was determined using the formula;

$\%$ Yield $=\frac{\text { Weight of microsphere obtained }}{\text { Sum of weight of polymer and drug }} \times 100$

\section{Scanning electron microscopic (SEM) studies}

Drug loaded microspheres were subjected for SEM studies using JEOL JSM-6360 to analyse the surface morphology of microspheres.

\section{Entrapment Efficiency}

Drug entrapment in the microspheres was determined in terms of percentage drug entrapment for each batch of formulation using the formula; ${ }^{11}$

$\% \mathrm{EE}=\frac{\text { Practical drug content of microsphere }}{\text { Total amount of drug incorporated }} \times 100$ $100 \mathrm{mg}$ of prepared microspheres were triturated in mortar and pestle then transferred to $100 \mathrm{ml}$ of $7.4 \mathrm{pH}$ phosphate buffer placed on magnetic stirrer for $1 \mathrm{~h}$ to extract the drug, it was then filtered and drug content determined.

\section{Differential scanning colorimetric (DSC) studies}

DSC was performed for pure drug and optimized drug loaded microspheres to check the interaction between drug and polymers used (Shimadzu, Japan). Sample was placed in aluminium pans and the lids were crimped using a Shimadzu crimper. Thermal behaviour of the samples was explored under nitrogen purge at scanning rate of $10^{\circ} \mathrm{C} / \mathrm{min}$ and in the temperature range of $30-320^{\circ} \mathrm{C}$. Empty aluminium pans were used as reference. ${ }^{16,17}$

\section{Fourier transform infrared spectrum}

FT-IR (IR affinity-1Shimadzu) analysis was done to check the chemical interaction between drug and polymers. IR spectra was obtained for pure drug, chitosan, cellulose acetate phthalate, drug loaded microspheres and tableted microsphere. Sample was mixed thoroughly with $100 \mathrm{mg}$ potassium bromide, IR was performed under vacuum at a pressure of about 12,000 psi for $3 \mathrm{~m}$. base line correction was made using dried potassium bromide, the IR spectrum was obtained by scanning from $4000 \mathrm{~cm}^{-1}$ to $625 \mathrm{~cm}^{-1}$.

\section{Swelling Index (SI)}

Weighed quantity of microspheres were placed in buffer solution of $\mathrm{pH} 7.4$ for $24 \mathrm{~h}$ to allow swelling. The microspheres were filtered and weighed. Further, the microspheres were then dried in hot air oven at $40^{\circ} \mathrm{C}$ until there was no alteration in dried mass of sample. ${ }^{18}$ The swelling index was calculated using following equation;

$\%$ Swelling index $=$

Mass of microshperes after sweeling-mass of dry microspheres

Sum of dry microspheres

\section{Flow property for microspheres}

The flow property for microspheres was studied by determining Bulk density, Tapped density, Angle of repose, Carr's Index and Hausner's Ratio. ${ }^{18}$ Bulk density and tapped density was determined using graduated cylinder; angle of repose using fixed funnel method.

\section{In-vitro dissolution studies of microsphere}

In vitro dissolution study was performed using USP type II (Paddle type) apparatus (LABINDIA ${ }^{\circledR}$ DS 8000) set at $50 \mathrm{rpm}$ and $37 \pm 0.5^{\circ} \mathrm{C}$. Weight of microspheres equivalent to $3 \mathrm{mg}$ of Budesonide was taken for study. The drug release from microspheres was checked by performing dissolution study for $2 \mathrm{~h}$ in $0.1 \mathrm{~N} \mathrm{HCl}$ and 10 $\mathrm{h}$ in $\mathrm{pH}$ 7.4 PBS. Sampling was done at predetermined time and sink condition was maintained. Aliquot was suitably diluted and absorbance for samples measured using Shimazdu UV 1900 Spectrophotometer at 247 nm. ${ }^{19}$

\section{Model fitting analysis for in vitro release data}

The results obtained from in vitro dissolution study data was analyzed for its release kinetic by fitting the release data into zero order, first order, matrix, HixsonCrowell cube root equation and Ritger-Peppas equation to find out the $r^{2}$ value and the best fit model of release kinetic for drug from the prepared microspheres. Disso software was used for Model fitting.

\section{Compression of formulated microspheres into tablets by direct compression method}

$250 \mathrm{mg}$ tablet of optimized formulation of microspheres F4 (polymer ratio 3:5 and surfactant concentration 1.5\%) were compressed using microcrystalline cellulose and magnesium stearate. Microspheres equivalent to $3 \mathrm{mg}$ Budesonide was taken and compressed using RIMEK MINI PRESS-1 using $8 \mathrm{~mm}$ punches size. Formula for preparation of tablet is given in Table 3. The tablets were then coated with $5 \%$ cellulose acetate phthalate to prevent disintegration of tablet and drug degradation in stomach. ${ }^{20}$

\section{Pre-compression tests for tablet granules}

\section{Powder flow properties}

To study the flow properties of powder bulk density, tapped density, carr's index, hausner's ratio and angle of repose was determined. 


\begin{tabular}{|c|c|}
\hline \multicolumn{2}{|c|}{ Table 3: Composition for compressed tablet of } \\
microspheres.
\end{tabular}

\section{Post-compression tests for tablets}

\section{In vitro drug release studies for tablets}

The in-vitro dissolution studies of tablets compressed for optimised microsphere and marketed product was performed using USP type II apparatus set at $50 \mathrm{rpm}$ at $37 \pm 0.5^{\circ} \mathrm{C}$. The dissolution studies were performed for $2 \mathrm{~h}$ in $0.1 \mathrm{~N} \mathrm{HCl}$ followed in $7.4 \mathrm{pH}$ PBS for 10 h. The samples were withdrawn at predetermined time interval and replaced with equal quantity of buffer solution. The samples were suitably diluted and percent drug released was determined using Shimazdu UV 1900 UV-spectrophotometer at $247 \mathrm{~nm} .{ }^{19}$

\section{In vitro disintegration test}

Disintegration time for compressed uncoated and coated tablets was determined using disintegration test apparatus. Compressed tablets were placed in baskets immersed in $900 \mathrm{ml}$ of $0.1 \mathrm{~N} \mathrm{HCl}$. The study was performed for $2 \mathrm{~h}$ at $37 \pm 2^{\circ} \mathrm{C}$.

\section{Weight variation}

20 compressed tablets were selected randomly and all tablets were weighed individually. The percentage variation was determined by calculating difference between individual weights of tablet with average weight of 20 tablets. The percentage variation was determined using formula;

$\%$ Weight variation $=\frac{\text { Individual tablet weight-Average weight }}{\text { Average weight }} \times 100$

\section{Friability test}

Compressed uncoated tablets were subjected to friability test using Roche friabilator. Initial weight of 20 uncoated tablets was noted and loaded in friabilator, operated at $25 \mathrm{rpm}$ for $4 \mathrm{~m}$. Tablets are then de-dusted, weighed and difference in weight was noted. The formula used to determine friability.

Friability $=\frac{\mathrm{W}_{1}-\mathrm{W}_{2}}{\mathrm{~W}_{1}} \mathrm{X} 100$

Where, $\mathrm{W}_{1}=$ Initial weight of tablets

$\mathrm{W}_{2}$ Final weight of tablets

\section{Drug content uniformity}

Drug content of compressed uncoated tablets was determined by powdering 5 randomly selected tablets, weight of the powder equal to mean weight of 5 tablets was then transferred to $100 \mathrm{ml}$ of $\mathrm{pH} 7.4$ phosphate buffer in volumetric flask, dissolve completely on a mechanical shaker. The solution is then filtered, suitably diluted and absorbance measured using UVspectrophotometer at $247 \mathrm{~nm}$.

\section{Hardness test}

Monsanto hardness tester was used to determine hardness of the tablets and the values were determined in triplicate.

\section{Thickness test}

The vernier calipers was used to test the thickness of tablets. 3 tablets were randomly tested for their thickness and average value was considered.

\section{Percentage weight gain of tablet}

The optimized microspheres were compressed to tablets which was further coated by dip coating method using cellulose acetate phthalate as enteric coating material. The percentage weight gain of tablet after coating was determined using formula

$\%$ Weight gain $=\frac{\text { Weight of coated tablet }- \text { weight of uncoated tablet }}{\text { Weight of coated tablet }} \times 100$

\section{Accelerated stability testing}

The formulated tablets were checked for their stability by keeping the formulation at $40 \pm 2^{\circ} \mathrm{C}$ and $75 \pm 5 \% \mathrm{RH}$ in stability chamber for 1 month. The tablets were then analyzed after every 10 days for its drug content and in vitro drug release study.

\section{RESULTS AND DISCUSSION}

The identity of drug was confirmed with its melting point found to be \pm 1.414 with no significant deviation from literature value of $226^{\circ} \mathrm{C}$. Beer's concentration range for drug was in the range of $2-10 \mu \mathrm{g} / \mathrm{ml}$. A linear calibration curve was obtained in $\mathrm{pH} 7.4$ phosphate buffer solution with $r^{2}$ value of 0.9989 .

\section{Flow properties of microspheres}

Results of flow property of microspheres studied for carr's index, hausner's ratio and angle of repose is tabulated in Table 4. Angle of repose for all formulations was ranging from $30.33^{\circ} \pm 1.814$ to $41.82^{\circ} \pm 0.012$ which shows good to poor flow property of microspheres, the poor flow may be due to irregular shape and porous nature of microspheres formed by emulsion solvent 


\begin{tabular}{c|c|c|c|}
\multicolumn{4}{|c}{ Table 4: Evaluation of formulated microspheres for } \\
flow properties. \\
$\begin{array}{c}\text { Formulation } \\
\text { code }\end{array}$ & $\begin{array}{c}\text { Average } \\
\text { Carr's index } \\
\pm \text { SD }^{\mathrm{a}}\end{array}$ & $\begin{array}{c}\text { Average } \\
\text { Hausner's } \\
\text { ratio } \pm \text { SD }^{\mathrm{a}}\end{array}$ & $\begin{array}{c}\text { Average } \\
\text { angle of } \\
\text { repose } \pm \text { SD }^{\mathrm{a}}\end{array}$ \\
\hline F1 & $21.28 \pm 0.854$ & $1.27 \pm 0.0116$ & $35.03 \pm 1.475$ \\
\hline F2 & $8.63 \pm 0.0849$ & $1.09 \pm 0.00$ & $30.33 \pm 1.814$ \\
\hline F3 & $23.18 \pm 2.489$ & $1.30 \pm 0.0348$ & $35.55 \pm 2.713$ \\
\hline F4 & $26.85 \pm 0.715$ & $1.36 \pm 0.0173$ & $41.82 \pm 0.012$ \\
\hline F5 & $9.44 \pm 1.179$ & $1.11 \pm 0.012$ & $35.29 \pm 1.291$ \\
\hline F6 & $40.22 \pm 0.358$ & $1.673 \pm 0.010$ & $33.93 \pm 1.592$ \\
\hline F7 & $30.26 \pm 0.225$ & $1.433 \pm 0.005$ & $31.76 \pm 0.0058$ \\
\hline F8 & $4.27 \pm 1.718$ & $1.04 \pm 0.0205$ & $34.20 \pm 1.447$ \\
\hline F9 & $30.88 \pm 0.242$ & $1.446 \pm 0.005$ & $40.53 \pm 1.815$ \\
\hline
\end{tabular}

Where, $\mathrm{SD}^{\mathrm{a}}=$ standard deviation from the mean $(n=3)$

evaporation method. The Carr's index ranged between $4.27 \pm 1.718$ to $40.22 \pm 0.358$ indicating excellent to poor compressibility of microspheres. Poor compressibility may be due to cellulose acetate phthalate in the polymer matrix of microspheres. The optimized formula shows the compressibility of $26.85 \pm 0.715$ which indicates poor compression, which was improved using microcrystalline cellulose as a directly compressible diluent to form a tablet with acceptable hardness. Hausner's ratio varies from $1.04 \pm 0.0205$ to $1.673 \pm 0.010$ indicating good flow for 1.04 as per IP criteria and poor flow for 1.673. Hausner's value indicates flow cannot be improved by addition of glidants. The optimized formulation showed the Hausner's ratio of 1.36 which indicates that flow of the microspheres can be enhanced by the addition of glidant.

\section{FT-IR results}

Interpolymer complexation and drug excipient interactions were confirmed by FT-IR analysis as depicted in Figure 1. A characteristic peak of $\mathrm{C}=\mathrm{O}$ stretching of phthalate group at $1743.65 \mathrm{~cm}^{-1}$ was observed for cellulose acetate phthalate (Figure 1a) and for chitosan the sharp peak at $3373 \mathrm{~cm}^{-1}$ which is due to $-\mathrm{N}-\mathrm{S}$ - stretching of amine group (Figure $1 \mathrm{~b}$ ). The drug loaded microsphere (Figure 1a) showed the absence of characteristic peak of both chitosan and cellulose acetate phthalate which indicate formation of interpolymer complex between the two polymers. In FT-IR study (Figure 1c). Budesonide exhibits a peak at $3500.80 \mathrm{~cm}^{-1}$ which is corresponding to alcoholic $\mathrm{OH}$ group. Presence of broad peak from $2956.87 \mathrm{~cm}^{-1}$ to $2872.01 \mathrm{~cm}^{-1}$ due to $\mathrm{C}-\mathrm{H}$ for $\mathrm{CH}_{2}$ and $-\mathrm{CH}_{3}$ groups. Peaks at $1724.36 \mathrm{~cm}^{-1}$ and $1666.50 \mathrm{~cm}^{-1}$ characteristic peaks of $-\mathrm{C}=\mathrm{O}$ group due to ketone and strong

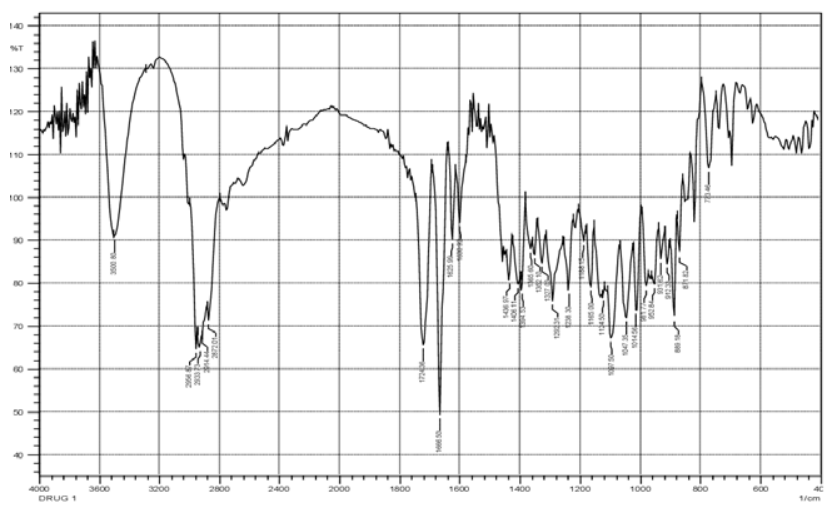

Figure 1(a): FTIR spectrum of Cellulose Acetate Phthalate.

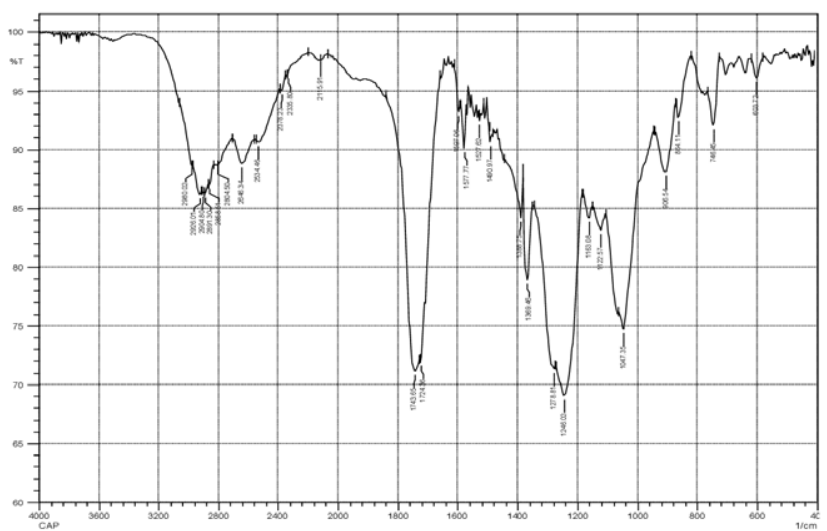

Figure 1(b): FTIR spectrum of Chitosan.

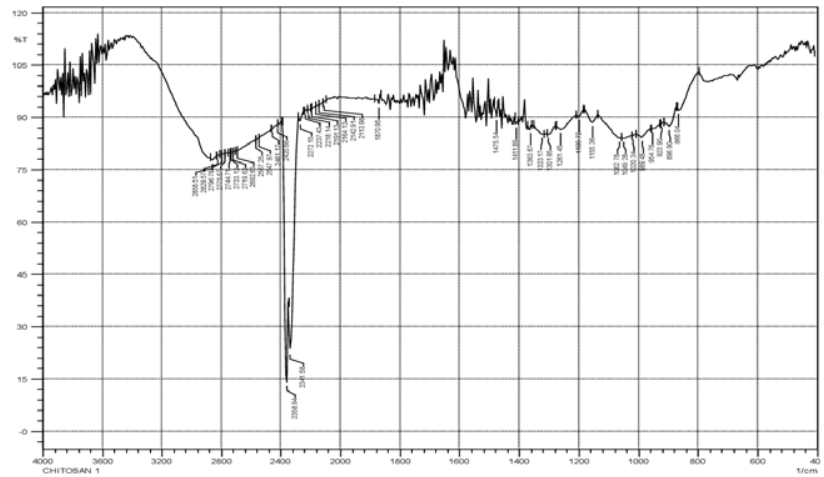

Figure 1(c): FTIR spectrum of pure Budesonide.

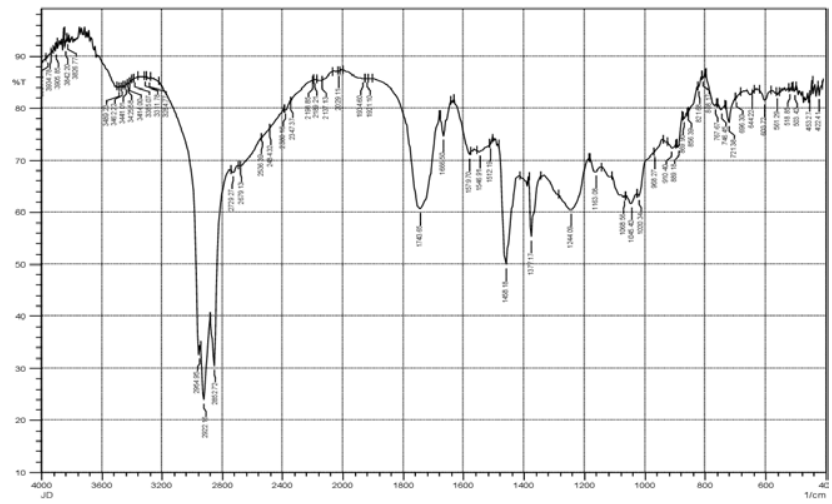

Figure 1(d): FTIR spectrum of budesonide loaded Microsphere. 
peak at $1097.50 \mathrm{~cm}^{-1}$ due to $\mathrm{C}-\mathrm{O}-\mathrm{C}$ of ether. All the corresponding peaks relevant to drug were present in the final formulation of microsphere (Figure 1d) which indicate chemical stability between drug and polymers.

\section{Differential scanning calorimetry}

Nature of pure drug and interaction between drug and polymers was confirmed by DSC study, spectra obtained as depicted in Figure $2 \mathrm{a}$ and Figure 2b. The spectra for pure drug showed sharp endothermic peak at around $260^{\circ} \mathrm{C}$ which resembles melting point of pure drug whereas for the microspheres no sharp peak was observed due to dispersion of drug in the interpolymer complex matrix.

\section{Scanning electron microscopy}

SEM images as shown in Figure 3 for drug loaded microspheres reveals formation of round microspheres with pervious and uneven surfaces. The pervious surface is due to evaporation of acetone from the matrix during formation of the microspheres.

\section{Percentage yield}

The efficacy of method for preparation of microspheres is reflected by the percentage yield obtained. The yield was found to be in the range of $46.42 \pm 0.089$ to $81 \pm 0.090 \%$ with the highest yield for $\mathrm{F} 7$ (polymer ratio $3: 5$ and surfactant concentration $2 \%$ ). Results are shown in Table 5.

\section{Percentage encapsulation efficiency}

Dissolution rate of drug is dependent on the encapsulation efficiency of the microspheres. Results for drug content and percentage encapsulation efficiency are tabulated in Table 5. The drug content was found to be in the range of $2.37 \pm 0.0263$ to $8.68 \pm 0.0374$ with the highest drug content of 8.68 for formulation F4 (polymer ratio 3:5, surfactant concentration 1.5\%), it showed highest percentage encapsulation efficiency of $53.64 \pm 0.228$ and highest drug release from the microspheres. Increase in polymer ratio showed higher drug encapsulation.

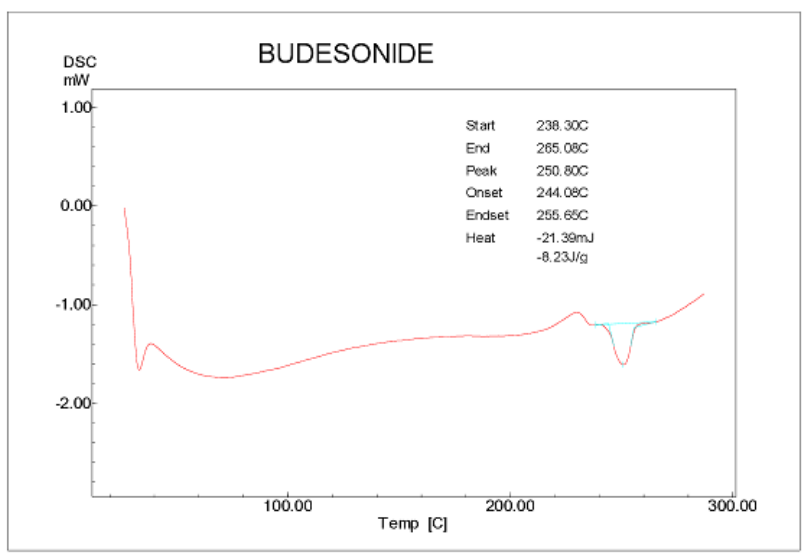

Figure 2(a): DSC Thermogram of pure Drug.

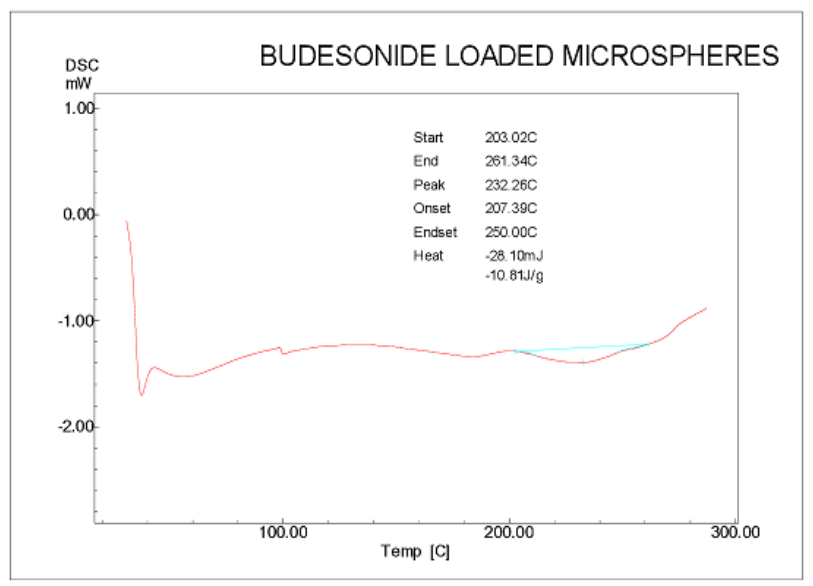

Figure 2(b): DSC Thermogram of Budesonide loaded Microsphere.

\begin{tabular}{|c|c|c|c|c|c|}
\hline \multicolumn{7}{|c|}{ Table 5: Physico-chemical evaluation of formulated microspheres. } \\
\hline $\begin{array}{c}\text { Formulation } \\
\text { code }\end{array}$ & $\begin{array}{c}\text { Average } \\
\text { Drug content } \\
(\mathbf{m g}) \pm \text { SD }^{\mathbf{a}}\end{array}$ & $\begin{array}{c}\text { Average } \\
\% \text { EE } \pm \text { SD }^{\mathbf{a}}\end{array}$ & $\begin{array}{c}\text { Average Swelling } \\
\text { index } \\
(\%) \pm \text { SD }^{\mathrm{a}}\end{array}$ & $\begin{array}{c}\text { Average Particle } \\
\text { size } \\
(\mu \mathrm{m}) \pm \text { SD }^{\mathrm{a}}\end{array}$ & $\begin{array}{c}\text { Average } \\
\% \text { Yield } \pm \text { SD }^{\mathrm{a}}\end{array}$ \\
\hline F1 & $4.83 \pm 0.0340$ & $26.34 \pm 0.187$ & $56 \pm 4.163$ & $49.56 \pm 0.882$ & $60.46 \pm 0.0974$ \\
\hline F2 & $2.99 \pm 0.089$ & $18.69 \pm 0.563$ & $66.67 \pm 4.109$ & $101.75 \pm 0.101$ & $62.5 \pm 0.00$ \\
\hline F3 & $8.1 \pm 0.0653$ & $37.26 \pm 0.302$ & $84 \pm 4.32$ & $118.40 \pm 0.814$ & $57.84 \pm 0.259$ \\
\hline F4 & $8.68 \pm 0.0374$ & $53.64 \pm 0.228$ & $48.67 \pm 2.494$ & $68.74 \pm 0.961$ & $68.69 \pm 0.159$ \\
\hline F5 & $4.28 \pm 0.028$ & $30.60 \pm 0.202$ & $60 \pm 1.63$ & $102.30 \pm 0.987$ & $71.5 \pm 0.00$ \\
\hline F6 & $4.48 \pm 0.0094$ & $45.70 \pm 0.0613$ & $84.67 \pm 6.84$ & $108.89 \pm 0.325$ & $46.42 \pm 0.089$ \\
\hline F7 & $5.34 \pm 0.0205$ & $38.95 \pm 0.148$ & $51.62 \pm 2.95$ & $82.47 \pm 1.212$ & $81 \pm 0.090$ \\
\hline F8 & $3.82 \pm 0.057$ & $25 \pm 0.376$ & $56.67 \pm 2.109$ & $102.38 \pm 0.587$ & $65.5 \pm 0.00$ \\
\hline F9 & $2.37 \pm 0.0263$ & $27.54 \pm 0.193$ & $87.33 \pm 3.40$ & $111.85 \pm 0.651$ & $52.76 \pm 0.0579$ \\
\hline
\end{tabular}

Where, $\mathrm{SD}^{\mathrm{a}}=$ standard deviation from the mean $(\mathrm{n}=3)$ 


\section{Mean particle size of microspheres}

Mean particle size was found in the range of $49.56 \pm 0.882$ $\mu \mathrm{m}$ for lower ratios of polymers i.e. 3:5 (CS: CAP) to $118.40 \pm 0.814 \mu \mathrm{m}$ for higher ratio of polymers i.e. 5:5 (CS: CAP). Results shown in Table 5. The results indicated that particle size of microsphere increased with increase in polymer concentration. Surfactant concentration in the formulation does not show significant effect on the particle size. Hence it is only dependent on the ratio of polymers in the formation of microspheres.

\section{Swelling index}

The swelling index of microspheres showed its dependence on the concentration of chitosan present in the formulation due to its water holding and swelling capacity in the matrix. Swelling index was found to be independent with respect to concentration of cellulose acetate phthalate in the microsphere due to its water hating i.e. hydrophobic nature. The microspheres showed minimum swelling index of $48.67 \pm 2.494 \%$ for F4 which contains 3 parts of chitosan and maximum of $87.33 \pm 3.40 \%$ for microspheres containing 5 parts of chitosan in the formulation. Results for swelling index are shown in Table 5.

\section{Post compression evaluation of tablets}

Results of evaluation tests for uncoated and coated tablets are tabulated in Table 6. Compressed uncoated tablets were found to disintegrate within $20 \mathrm{~min}$, as compared to compressed coated tablets with disintegration time more than $75 \mathrm{~min}$. There was slight weight gain for coated tablets and friability was found to decrease due to coating of tablets.

\section{In vitro drug release study}

Dissolution studies of microspheres revealed that the release of drug in $\mathrm{pH} 1.2(0.1 \mathrm{~N} \mathrm{HCl})$ was prevented due to altered physico-chemical properties of polymer by formation of interpolymer complex and showed the maximum release of drug from microspheres in $\mathrm{pH} 7.4$ buffer indicating that maximum concentration of drug will reach colon with minimum loss and degradation of drug in upper GIT i.e. stomach.

Release data obtained from varying polymer ratio and surfactant concentration has been depicted in Figure 4 ( $a, b$ and $c$ ) which showed that the highest drug release was observed with the microspheres containing low amount of chitosan i.e. 3:5 with all three levels of surfactant concentration $(1 \%, 1.5 \%$ and $2 \%)$ i.e. F1, F4 and F7. The release of drug from the microspheres was dependent upon the chitosan concentration which acts as release retardant excipient in the microsphere formulation. The results showed that as the chitosan ratio in the microsphere increases release of drug from the microsphere decreases.

For the microsphere formulations with 5:5 polymer ratio (CS:CAP) at varied surfactant concentration i.e. F3, F6 and F9 showed slow release of drug from the formulation. Slow release is due to increased ratio of chitosan in the microspheres which results in the formation of rigid complex which retards instant drug release from the formulation. The cellulose acetate phthalate in the complex undergoes dissolution in intestinal $\mathrm{pH}$ and enzymatic degradation of chitosan in the colon causes drug to release at target site.

Surfactant concentration does not show much effect on drug release, but slight increase in the release was observed for the microspheres containing $2 \%$ in comparison to 1 and $1.5 \%$ surfactant concentration, indicating drug release is highly dependent on polymer ratio.

Prepared microspheres showed release of the drug for up to $12 \mathrm{~h}$ with small amount of drug release in $\mathrm{pH}$ 1.2 buffer which may be due to adsorbed drug on the surface of microspheres. Hence, the novel interpolymer complex microsphere can be promising for colon delivery without releasing drug in stomach.

In vitro release profile of compressed coated tablet containing optimised microspheres was compared with

\begin{tabular}{|c|c|c|}
\hline \multicolumn{2}{|c|}{ Table 6: Evaluation for Compressed tablets of optimised microspheres. } \\
\hline Evaluation tests & For uncoated tablets & For CAP coated tablets \\
\hline Weight variation $(\%) \pm \mathrm{SD}^{\mathrm{a}}$ & 0.773 & 7.07 \\
\hline Disintegration time $(\mathrm{min}) \pm \mathrm{SD}^{\mathrm{a}}$ & $19.33 \pm 1.247$ & $0.215 \pm 0.076$ \\
\hline Friability $(\%) \pm \mathrm{SD}^{\mathrm{a}}$ & $0.508 \pm 0.0557$ & $4.46 \pm 0.0489$ \\
\hline Thickness $(\mathrm{mm}) \pm \mathrm{SD}^{\mathrm{a}}$ & $4.43 \pm 0.0291$ & $4.45 \pm 0.0$ \\
\hline Hardness $(\mathrm{kg} / \mathrm{cm} 2) \pm \mathrm{SD}^{\mathrm{a}}$ & $4.0 \pm 0.0$ & $2.77 \pm 0.0339$ \\
\hline Drug content $(\mathrm{mg}) \pm \mathrm{SD}^{\mathrm{a}}$ & $2.77 \pm 0.0339$ & 5.17 \\
\hline Weight gain after coating $(\%) \pm \mathrm{SD}^{\mathrm{a}}$ & - & \\
\hline
\end{tabular}

Where, $\mathrm{SD}^{\mathrm{a}}=$ standard deviation from the mean $(n=3)$. 


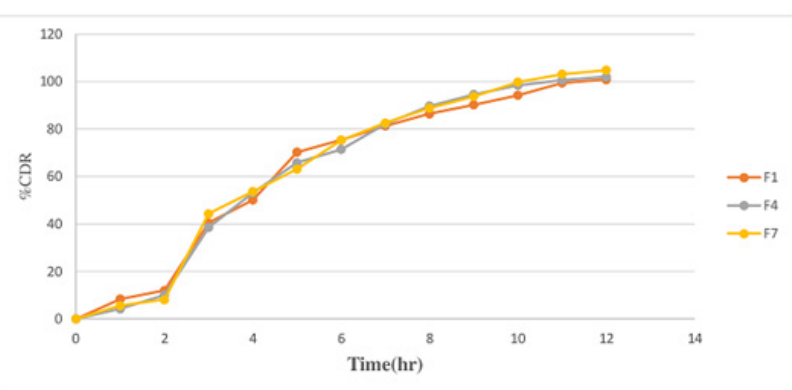

Figure 4(a): Drug release profile for formulated microsphere F1, F4 and F7.

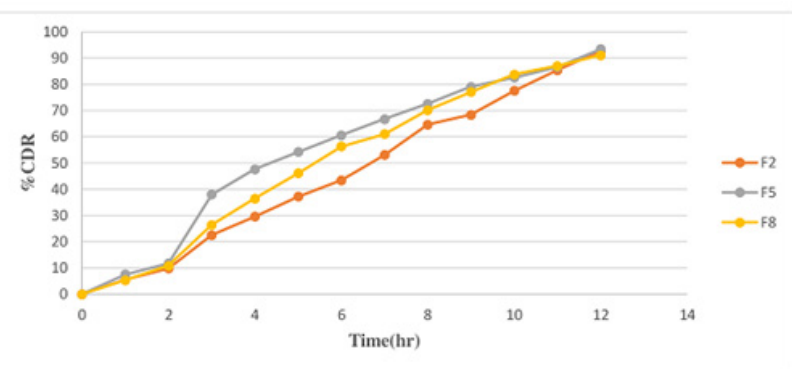

Figure 4(b): Drug release profile for formulated microsphere F2, F5 and F8.

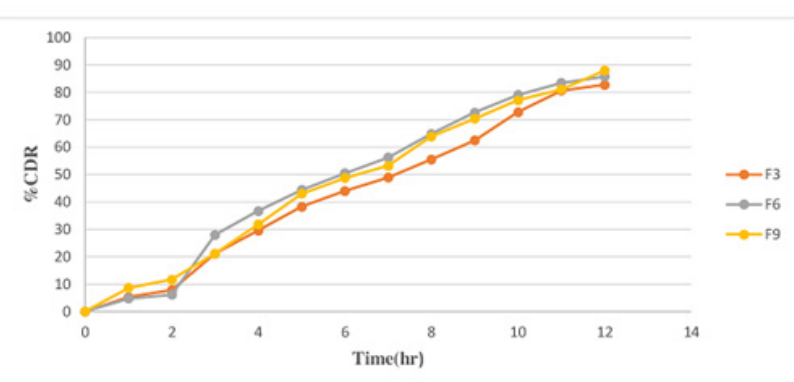

Figure 4(c): Drug release profile for formulated microsphere F3, F6 and F9.

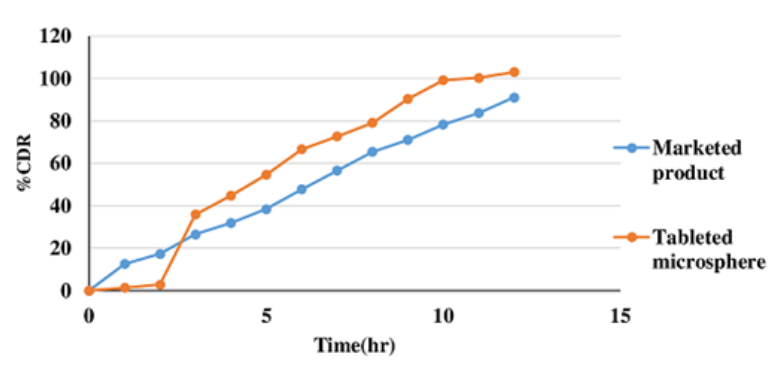

Figure 5: Comparative drug release profile of compressed coated tablets of Budesonide with its marketed product.

marketed product of Budenoside and results depicted in Figure 5. The release of the drug from the tablet coated with cellulose acetate phthalate as enteric coating material does not disintegrate in $\mathrm{pH}$ 1.2. It completely prevents drug release and its degradation in $\mathrm{pH} 1.2$. As the tablet moves into intestinal $\mathrm{pH}$, the solubility of cellulose acetate phthalate in intestine $\mathrm{pH}$ results in release of drug which is available for absorption in the colon. Whereas marketed product was found to disintegrate when in contact with gastric contents and showed release of the drug in $\mathrm{pH} 1.2$ buffer indicating drug degradation in the stomach and hence ineffective concentration reaching colon for absorption.

\section{Factorial design}

The effect of polymer ratio and surfactant concentration on $\% \mathrm{CDR}, \% \mathrm{EE}$ and mean particle size was analysed with the help of 3D surface response method, 2D contour plot, perturbation plot and effect of individual factor on the response.

The result for $\%$ CDR indicates that drug release from microsphere is inversely proportional to polymer

Table 7: Model fitting analysis for drug release mechanism.

\begin{tabular}{|c|c|c|c|c|c|c|c|}
\hline Formulations & Zero order & First & Matrix & Peppas & $\begin{array}{l}\text { Hixson- } \\
\text { crowell }\end{array}$ & N & K \\
\hline F1 & 0.9476 & 0.8703 & 0.9499 & 0.9566 & 0.9285 & 1.0658 & 9.2137 \\
\hline F2 & 0.9970 & 0.9135 & 0.9118 & 0.9939 & 0.9596 & 1.1665 & 5.4495 \\
\hline F3 & 0.9957 & 0.9552 & 0.9192 & 0.9868 & 0.9781 & 1.1706 & 5.0574 \\
\hline F4 & 0.9571 & 0.9306 & 0.9450 & 0.9551 & 0.9303 & 1.1435 & 7.8932 \\
\hline F5 & 0.9655 & 0.9691 & 0.9568 & 0.9638 & 0.9919 & 1.0294 & 8.5788 \\
\hline F6 & 0.9848 & 0.9722 & 0.9297 & 0.8641 & 0.9876 & 1.4002 & 4.1161 \\
\hline F7 & 0.9576 & 0.8221 & 0.9429 & 0.9426 & 0.9118 & 1.2481 & 6.5436 \\
\hline F8 & 0.9254 & 0.9179 & 0.8778 & 0.8043 & 0.9351 & 1.0497 & 6.6016 \\
\hline F9 & 0.9958 & 0.9591 & 0.9326 & 0.9897 & 0.9840 & 1.0116 & 7.4915 \\
\hline $\begin{array}{c}\text { Compressed coated tablet of } \\
\text { microspheres }\end{array}$ & 0.9755 & 0.8399 & 0.9221 & 0.9194 & 0.9039 & 2.0003 & 1.7320 \\
\hline Marketed product (Tablet) & 0.9966 & 0.9437 & 0.9414 & 0.9926 & 0.9785 & 0.8489 & 10.7206 \\
\hline
\end{tabular}

Where $\mathrm{N}=$ diffusional exponent value and $\mathrm{K}=$ release kinetic constant. 

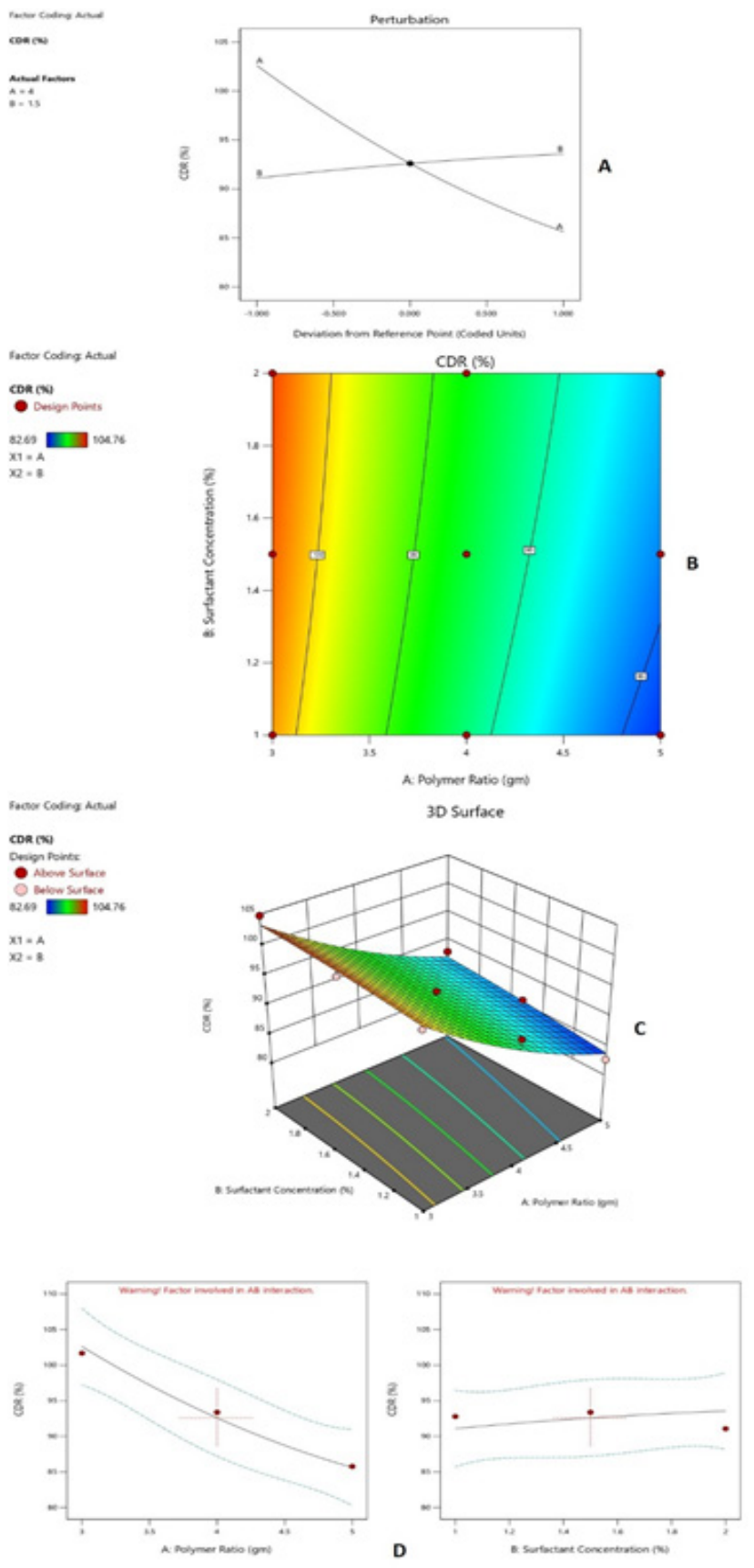

Figure 6: Effect of polymer ratio and surfactant concentration on \%CDR (a) perturbation plot (b) contour plot (c) 3D response surface plot (d) effect of individual factor on \%CDR.

concentration. This is due to the formation of more rigid complex as the polymer composition in the microspheres increases. Increase in surfactant concentration showed no significant variation in drug release indicating polymer ratio as the main contributing factor in the drug release. Perturbation plot and individual response plot depicted in Figure 6 shows little increase in the \% CDR as surfactant concentration increases.

The effect of polymer ratio on $\% \mathrm{EE}$ as shown in Figure 7 where maximum $\%$ EE was observed for 3:5 polymer
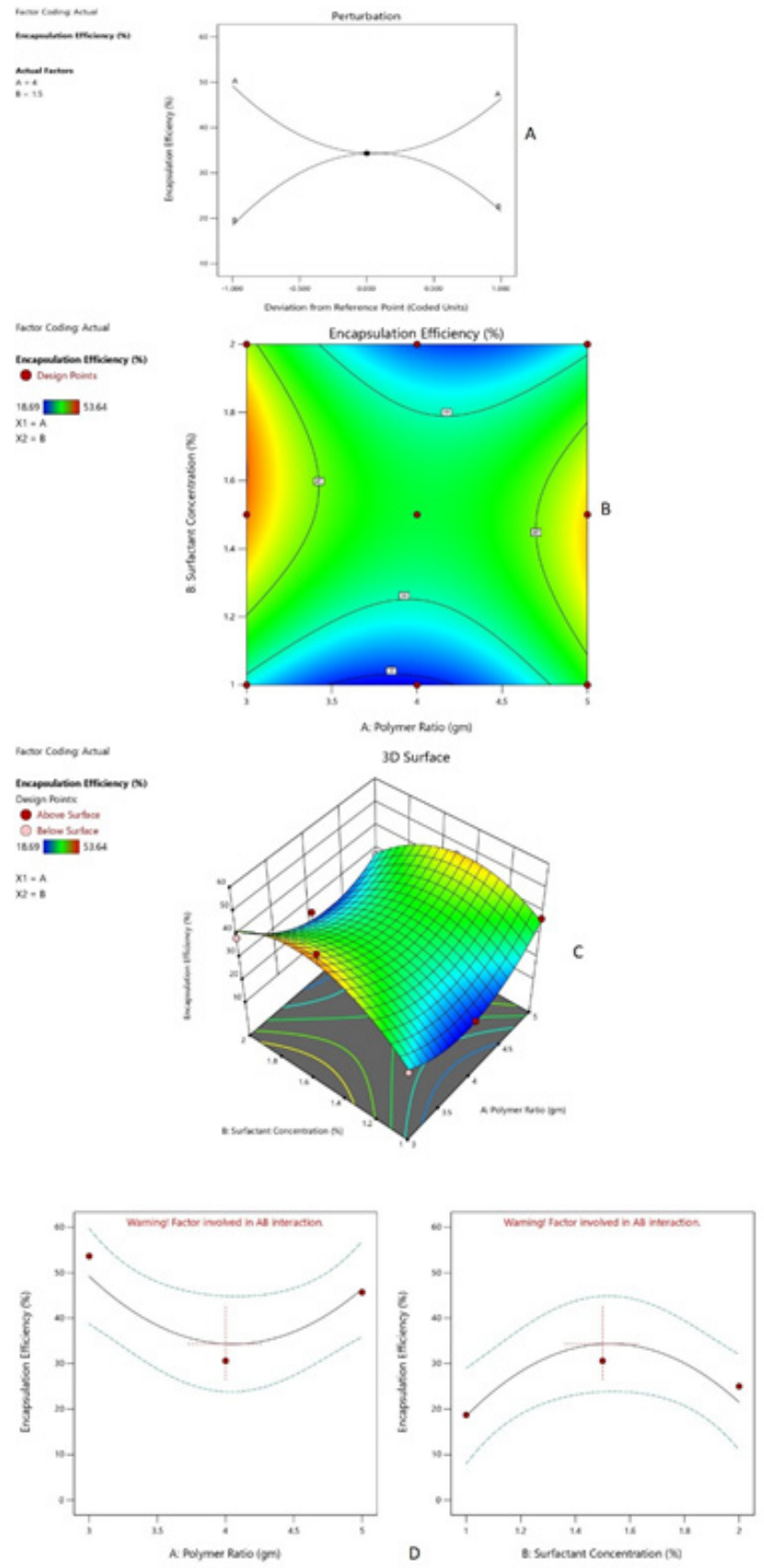

Figure 7: Effect of polymer ratio and surfactant concentration on \%EE (a) perturbation plot (b) contour plot (c) 3D response surface plot (d) effect of individual factor on \%EE

ratio. $\% \mathrm{EE}$ was found to increase with surfactant concentration up to $1.5 \%$ and decreases for further increase in concentration indicating both polymer ratio and surfactant concentration are contributing factors for $\% \mathrm{EE}$.

The particle size for different formulations of microsphere was studied and their results shown in Figure 8 reveals increase in the particle size as the polymer ratio in the microspheres increases due to formation of larger complexes of microspheres. 

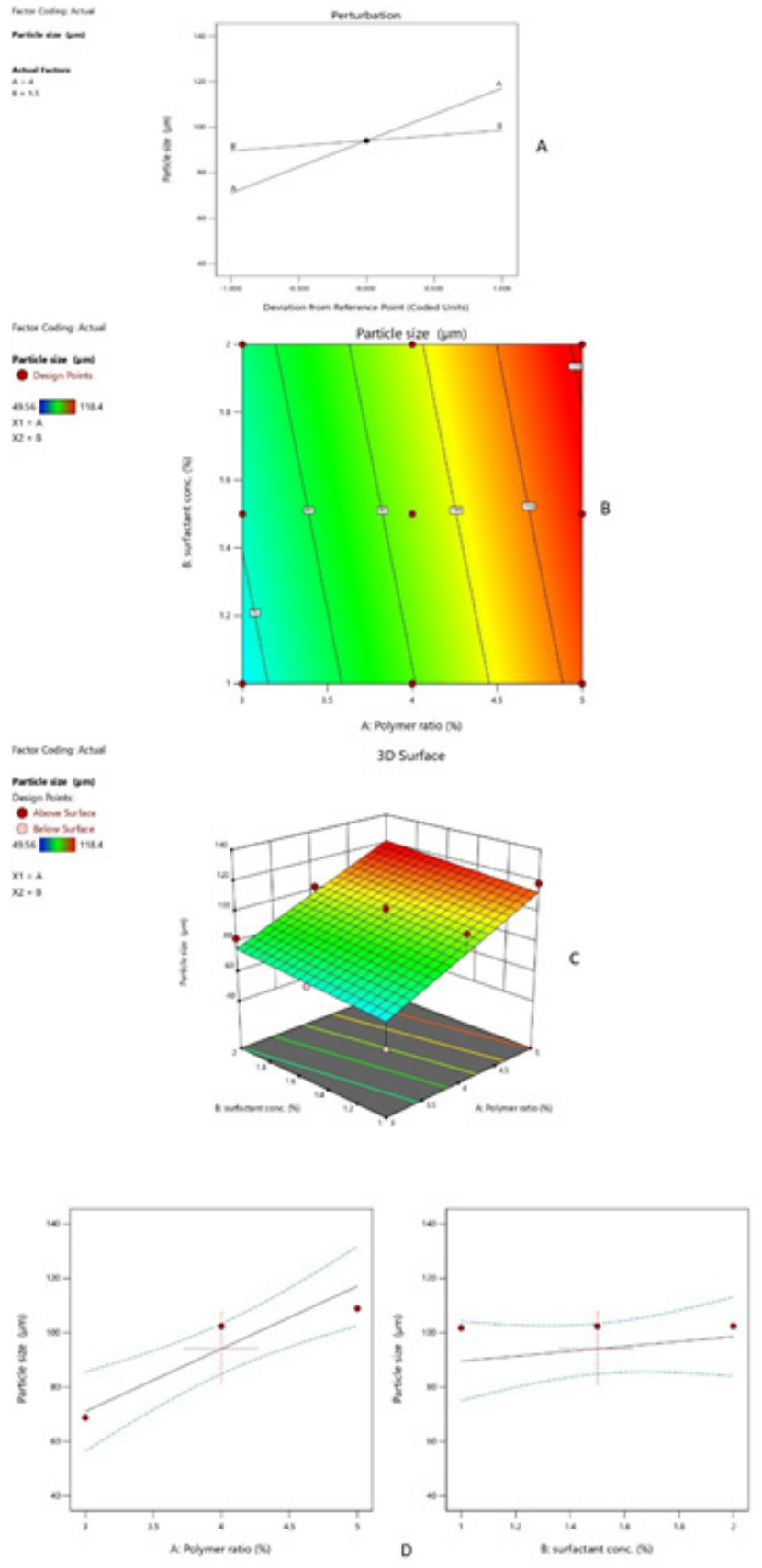

Figure 8: Effect of polymer ratio and surfactant concentration on mean particle size (a) perturbation plot (b) contour plot (c) 3D response surface plot (d) effect of individual factor on mean particle size.

Surfactant concentration does not show marked contribution to mean particle size of the microspheres. Hence both polymer ratio and surfactant concentration show individual effect on the responses.

\section{In vitro Release Kinetics}

Model fitting analysis for prepared microspheres as tabulated in Table 7 indicates varied release mechanisms. Drug release for formulated tablet was found to follow zero order release and Hixson-crowell cube root model for drug release kinetic.

\section{CONCLUSION}

Drug loaded microspheres for oral colon drug delivery was prepared by interpolymer complexation using emulsion solvent method. The microspheres help in the prevention of drug release in $1.2 \mathrm{pH}$ buffer by change in properties of the polymers involved in complex formation. Microspheres showed extended and complete release of drug in colon. Compressed coated tablets containing microspheres prevented drug release from the surface of microspheres in stomach. Hence, targeted drug delivery of Budenoside can be promising in enhancing efficacy of therapeutic effect.

\section{ACKNOWLEDGEMENT}

The authors thank to Cipla Private Limited, Goa, India for providing a gift sample of Budesonide.

\section{CONFLICT OF INTEREST}

The authors declare no conflicts of interest.

\section{ABBREVIATIONS}

CS: Chitosan; CAP: Cellulose acetate phthalate; IPC: Interpolymer complex; GIT: Gastrointestinal tract; Conc: Concentration; CDR: Cumulative drug release; \%: Percentage; $\mu$ g: Microgram; mg: Milligram; rpm: Rotation per minute; DSC: Differential scanning calorimetry; FTIR: Fourier transform infrared; h: Hour; m: Minute; $\lambda$ max: Maximum absorbance; $\mathbf{n m :}$ Nanometer; PBS: Phosphate buffer solution; EE: Encapsulation efficiency; SI: Swelling index.

\section{REFERENCES}

1. Vyas SP, Khar RK. Controlled drug delivery concepts and advances. Vallabh Prakashan. 2002;1:411-47.

2. Joshi M. Role of eudragit in targeted drug delivery. Int J Curr Pharm Res. 2013;5(2):58-62.

3. Jose S, Dhanya K, Cinu TA, Aleykutty NA. Multiparticulate system for colon targeted delivery of ondansetron. Indian J Pharm Sci. 2010;72(1):58.

4. Seth A, Jack EB, Vivek SD. Colon-Targeted Oral Drug Delivery Systems: Design Trends and Approaches. AAPS PharmSciTech 2015;16(4):731-41.

5. Mallikarjuna GM, Ramakrishna SA, Shantakumar SM, Somashekar SS, Putta RK. Development and validation of selective UV spectrophotometric analytical method for budesonide pure sample. J Appl Pharm Sci. 2011;1(7):158-61.

6. Prasanth VV, Jayaprakash R, Mathew ST. Colon specific drug delivery systems: A review on various pharmaceutical approaches. J Appl Pharm Sci. 2012;2(1):163-9.

7. Anita, Singh A, Dabral A. A review on colon targeted drug delivery system. Int J Pharm Sci Res. 2019;10(1):47-56.

8. http://www.drugbank.ca/drugs/DB0122. 
9. Park SH, Chun MK, Choi HK. Preparation of an extended-release matrix tablet using chitosan/Carbopol interpolymer complex. Int J App Pharm. 2000;347(1-2):39-44.

10. Srinivas L, Murthy KR. Preparation and evaluation of polyelectrolyte complexes for oral controlled drug delivery. Asian J Pharm. 2010;4(1):69-78.

11. Thakker SP, Rokhade AP, Abbigerimath SS, lliger SR, Kulkarni VH, More UA, et al. Inter-polymer complex microspheres of chitosan and cellulose acetate phthalate for oral delivery of 5-fluorouracil. Polymer Bulletin. 2014;71(8):211331.

12. O'Donnell PB, McGinity JW. Preparation of microspheres by the solvent evaporation technique. Adv Drug Deliv Rev. 1997;28(1):25-42.

13. Malik K, Goswami L, Kothiyal P. Formulation and Characterization of Clarithromycin Loaded Mucoadhesive Microspheres by Emulsification Solvent Evaporation for Anti-Helicobactor Pylori Therapy. Pharma Innovation. 2012;1(9):111.

14. Garud N, Garud A. Preparation and in-vitro evaluation of metformin microspheres using non-aqueous solvent evaporation technique. Trop J Pharm Res. 2012;11(4):577-83.
15. Ganguly K, Aminabhavi TM, Kulkarni AR. Colon targeting of 5-fluorouracil using polyethylene glycol cross-linked chitosan microspheres enteric coated with cellulose acetate phthalate. Ind Eng Chem Res. 2011;50(21):11797-807.

16. Chaurasia M, Chourasia MK, Jain NK, Soni V, Gupta Y, Jain SK. Crosslinked guar gum microspheres: A viable approach for improved delivery of anticancer drugs for the treatment of colorectal cancer. AAPS Pharm Sci Tech. 2006;7(3):143.

17. Kumar S, Kaur R, Sharma RK. Formulation and evaluation of Microspheres for Colon targeted delivery of Ondansetron. Int J Res Dev Pharm Life Sci. 2018;7(5):3083-91.

18. Krishnaiah YS, Reddy PB, Satyanarayana V, Karthikeyan RS. Studies on the development of oral colon targeted drug delivery systems for metronidazole in the treatment of amoebiasis. Int J Pharm. 2002;236(1-2):43-55.

19. Hamman JH. Chitosan based polyelectrolyte complexes as potential carrier materials in drug delivery systems. Marine Drugs. 2010;8(4):1305-22.

20. Shivangi S, Nithya S, Mahato AK. Formulation and evaluation of metronidazole tableted microspheres for colon drug delivery. Asian J Pharm Clin Res. 2016;9(3):2455-3891
PICTORIAL ABSTRACT

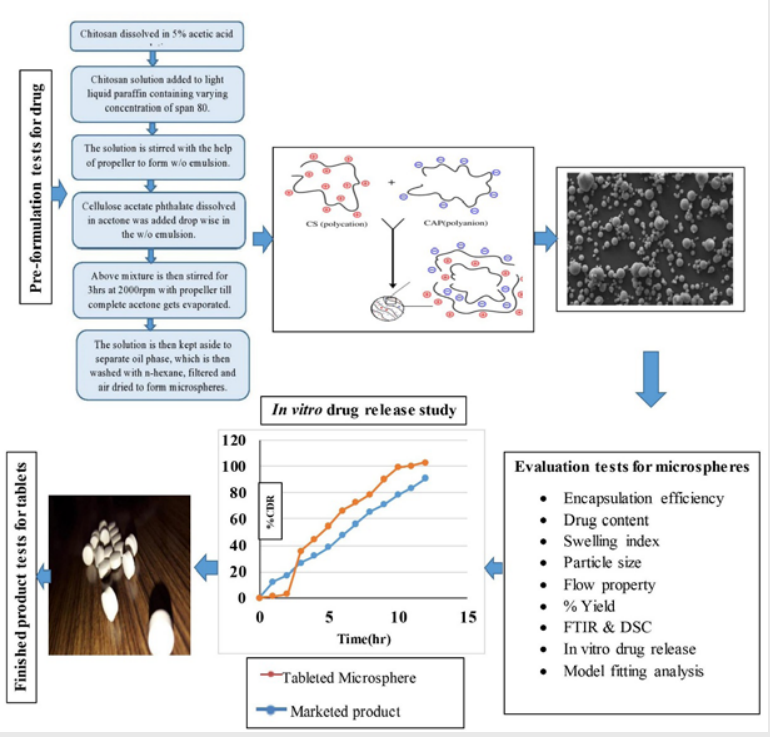

\section{SUMMARY}

- Emulsion solvent evaporation method was used to prepare interpolymer complex microspheres of Budesonide to prevent drug release in stomach.

- Microspheres prepared with 3:5 polymer ratios were found to be optimized with respect to drug content, \% encapsulation efficiency, Percentage yield and drug release.

- Drug and excipients compatibility and formation of complex between chitosan and cellulose acetate phthalate was assessed by FTIR spectral analysis.

- Compressed coated tablets of microspheres prevents drug release and its degradation in $\mathrm{pH}$ 1.2. Whereas released drug in 7.4 phosphate buffer in a sustaining manner.

- Compressed coated tablets were found to be stable at $40^{\circ} \mathrm{C}$ and $75 \%$ relative humidity and showed extended drug release up to $12 \mathrm{~h}$. Hence, Interpolymer complexation technique by emulsion solvent method can be promising for targeting drug release to colon.

\section{About Authors}

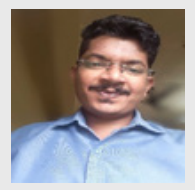

Mr. Ramgonda Patil was a Post graduate research scholar, completed his PG, in Department of Pharmaceutics, KLE College of Pharmacy, Belagavi, K.L.E Academy of Higher Education and Research, Belagavi.

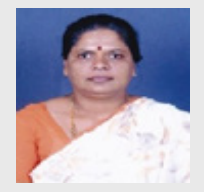

Prof. Rajashree S. Masareddy is a Professor and Head in the Department of Pharmaceutics, KLE College of Pharmacy, K.L.E Academy of Higher Education and Research, Belagavi. She is working in the area of Solubility enhancement techniques, gastroretentive systems and novel drug delivery systems.

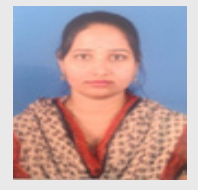

Dr. Archana S. Patil is an Assistant Professor, Department of Pharmaceutics, KLE College of Pharmacy, Belagavi, K.L.E Academy of Higher Education and Research, Belagavi. She is working in the area of targeted drug delivery systems $\mathrm{viz}, \mathrm{pH}$ and temperature responsive co-polymeric nanoparticles, pulsatile drug delivery systems as well as synthesis and characterization of graft co-polymers for intelligent drug delivery etc. 
Mr. Uday Baburao Bolmal is an Assistant Professor KLE College of Pharmacy, Constituent Unit of K.L.E Academy of Higher Education and Research, Belagavi. He is working on areas of targeted drug delivery Devices to treat cancer, Design and Development of different models to study the pharmacokinetic studies. Formulation of herbal dental solutions and suspensions.

Cite this article: Ramgonda P, Masareddy RS, Patil A, Bolmal U. Development of Budesonide Oral Colon Specific Drug Delivery System using Interpolymer Complexation Method. Indian J of Pharmaceutical Education and Research. 2021;55(1s):s164-s175. 